\title{
PENENTUAN FISHING GROUND DAN ALAT TANGKAP UNGGULAN IKAN PELAGIS DI KOTA BENGKULU
}

\section{DETERMINATION FISHING GROUND AND SUPERIOR FISHING GEAR FOR PELAGIC FISH IN BENGKULU CITY}

\author{
Zerli Selvika ${ }^{1}$, Mustaruddin ${ }^{2}$, Roza Yusfiandayani ${ }^{2}$ \\ ${ }^{1}$ Program Studi Teknologi Perikanan Laut, \\ ${ }^{2}$ Departemen Pemanfaatan Sumberdaya Perairan, \\ Fakultas Perikanan dan Ilmu Kelautan, Intitut Pertanian Bogor \\ Korespondensi: zerliselvika@gmail.com
}

\begin{abstract}
The fisherman of Bengkulu city to hunt the fishing ground for pelagic was still conventionally. Pelagic fish was catched by many types of fishing gear. For optimalizing sustainable pelagic fisheries was required the information about fishing ground distribution and selecting superior fishing gear for pelagic fish. The purpose of this study was to find out the fishing ground distribution and selecting superior fishing gear for pelagic fish. The method was used to find out the fishing ground distribution by mapping and selecting superior fishing ground by scoring the result showed that the fishing ground of pelagic was around Tikus island, Mega island, and Enggano island. Based on the standardization result of technic, biology, social, and economic aspect showed that selected fishing gear as superior fishing gears for pelagic were purse seine, boat lift net, and troll line. The selected fishing gear for pelagic fish was superior fishing gear of all alternative fishing gear for pelagic fish.
\end{abstract}

Keyword: fishing ground, pelagic fish, superior fishing gear

\begin{abstract}
ABSTRAK
Nelayan Kota Bengkulu dalam pencarian fishing ground (daerah penangkapan ikan) ikan pelagis masih secara konvensional. Ikan pelagis ditangkap oleh beberapa jenis alat tangkap. Untuk mengoptimalkan perikanan pelagis secara berkelanjutan maka dibutuhkan informasi sebaran daerah penangkapan ikan dan pemilihan alat tangkap unggulan untuk ikan pelagis. Penelitian ini bertujuan untuk mengetahui sebaran daerah penangkapan ikan dan menentukan alat tangkap unggulan ikan pelagis. Metode yang digunakan untuk mengetahui sebaran daerah penangkapan ikan menggunakan pemetaan dan menentukan alat tangkap unggulan menggunakan metode skoring. Hasil penelitian menunjukkan bahwa daerah penangkapan ikan tersebar di sekitar Pulau Tikus, Pulau Mega, dan Pulau Enggano. Berdasarkan hasil standarisasi gabungan dari aspek teknik, biologi, sosial, dan ekonomi terpilih alat tangkap unggulan untuk ikan pelagis yaitu purse seine, bagan perahu, dan pancing tonda. Alat tangkap yang terpilih menjadi alat tangkap unggulan ikan pelagis merupakan alat tangkap yang unggul dari semua alternatif alat tangkap ikan pelagis.
\end{abstract}

Kata kunci: alat tangkap unggulan, daerah penangkapan ikan, ikan pelagis 


\section{PENDAHULUAN}

Hasil tangkapan ikan pelagis pada tahun 2017 adalah 16.966 ton (DKP Kota Bengkulu 2017). Pemanfaatan SDI dapat berjalan optimal dengan mengetahui salah satunya informasi Daerah Penangkapan Ikan (DPI) (Shabrina et al. 2017). Nelayan pada umumnya dalam penentuan DPI masih secara konvensional dan masih mencari-cari lokasi DPI, dimana DPI erat kaitannya dengan alat tangkap yang mampu menentukan tingkat keberhasilan dari kegiatan penangkapan (Ispahdianto et al. 2016). Adapun alat tangkap yang digunakan nelayan di Kota Bengkulu untuk menangkap ikan pelagis yaitu terdiri dari 50 payang, 12 purse seine, 1.325 gillnet, 145 jaring angkat, 73 rawai, dan 12 bagan perahu (DKP Kota Bengkulu 2017). Keanekaragaman alat tangkap yang digunakan dapat mengakibatkan munculnya konflik antar nelayan dan mengakibatkan degradasi lingkungan (Pregiwati et al. 2017; Dewanti et al. 2018). Penggunaan alat tangkap yang tidak ramah lingkungan dapat mendorong terjadinya ekploitasi yang berlebih terhadap sumber daya ikan.

Informasi tentang daerah penangkapan ikan di Kota Bengkulu perlu dieksplorasi agar penangkapan dapat berjalan lebih optimal dengan cara mengetahui sebaran daerah penangkapan ikan pelagis. Pengoptimalan alat tangkap yang digunakan perlu dilakukan penilaian kinerja alat tangkap unggulan untuk mengetahui alat tangkap yang paling tepat dan paling unggul untuk ikan pelagis. Fakta dilapangan menunjukkan belum ada informasi dari Dinas Kelautan dan Perikanan maupun dari Badan Pusat Statistik mengenai alat tangkap unggul berbasis sumber daya.

Untuk mendapatkan pijakan bagi pengembangan alat tangkap ikan pelagis, maka diperlukan suatu kajian yang dapat memberikan informasi dasar tentang sebaran daerah penangkapan ikan dan alat tangkap unggulan untuk ikan pelagis. Penelitian ini bertujuan menganalisis sebaran daerah penangkapan ikan untuk ikan pelagis dan menentukan alat tangkap unggulan untuk ikan pelagis. Hasil penelitian ini diharapkan dapat memberikan informasi sebaran daerah penangkapan ikan dan alat tangkap yang tepat untuk pemanfaatan ikan pelagis.

\section{METODE PENELITIAN}

\section{Waktu dan tempat penelitian}

Penelitian ini dilakukan di Kota Bengkulu dan waktu pengumpulan data lapang dilaksanakan pada SeptemberOktober 2018.

\section{Jenis dan sumber data}

Jenis data yang dikumpulkan pada penelitian adalah data primer dan data sekunder. Data primer dan data sekunder yang dibutuhkan adalah data aspek teknik, biologi, sosial, ekonomi, dan hasil produksi. Sumber data primer dan data sekunder berasal dari observasi, wawancara, dan studi pustaka.

\section{Pengumpulan data}

Pengumpulan data sebaran daerah penangkapan ikan dan alternatif alat tangkap unggulan dilakukan secara observasi dan wawancara kepada nahkoda kapal atau ABK. Nahkoda kapal ikan pelagis atau ABK untuk 1 responden mewakili 1 armada kapal. Pengambilan responden dengan proporsional minimal 5 responden dan maksimal 30 responden secara random sampling. data yang dikumpulkan untuk informasi sebaran daerah penangkapan ikan yaitu: 1) lokasi penangkapan; 2) waktu penangkapan dan; 3) daya jangkau penangkapan. Alternatif alat tangkap unggulan membutuhkan data yaitu: 1) aspek teknik (lama trip, metode penangkapan, daya jangkau penangkapan, spesies ikan dari masing-masing alat tangkap, penggunaan alat bantu dan bahan bakar); 2) aspek biologi (dampak terhadap habitat dan keanekaragaman, komposisi hasil tangkapan dan by-catch); 3) aspek sosial (dapat diterima secara sosial, jumlah ABK dan aspek hukum) dan; 4) aspek ekonomi (pendapatan per tip, biaya operasional per trip, kontinuitas usaha, dan pemasaran hasil tangkapan).

\section{Analisis data}

Pembuatan peta sebaran daerah penangkapan ikan pelagis menggunakan aplikasi ArcMap. Peta sebaran daerah 
penangkapan ikan pelagis dianalisis secara kualitatif. Sehingga mengetahui sebaran daerah penangkapan ikan pelagis yang ditangkap oleh nelayan Kota Bengkulu.

Penentuan alat tangkap unggulan menggunakan analisis skoring berdasarakan aspek teknik, biologi, sosial dan ekonomi (Mangkusubroto dan Trisnadi 1985 dalam Simbolon et al. 2011; Himelda et al. 2012) dengan rumus sebagai berikut:

$$
\begin{gathered}
V(X)=\frac{x-x o}{x 1-x o} \\
V(A)=\sum_{i=1}^{n} V i(X i) i=1,2,3, \ldots, n
\end{gathered}
$$

Keterangan:

$\mathrm{V}(\mathrm{X}) \quad$ : Fungsi nilai dari variabel $\mathrm{X}$

$\mathrm{X}$ : Nilai variabel $\mathrm{X}$

$\mathrm{X} 1$ : Nilai tertinggi pada kriteria $\mathrm{X}$

$\mathrm{XO}$ : Nilai terendah pada kriteria $\mathrm{X}$

$\mathrm{V}$ (A) : Fungsi nilai dari alternatif A

Vi (Xi) : Fungsi nilai dari alternatif pada kriteria ke-i
Kriteria-kriteria yang digunakan dalam aspek teknik, biologi, sosial, dan ekonomi dapat dilihat pada Tabel 1 . Kriteria-kriteria yang tidak menggunakan data riil diberi nilai skor. Pemberian data riil bertujuan dapat menggambarkan data sebenarnya dilapangan, sedangkan data yang bersifat kualitatif diberikan skor. Data riil yang diberikan adalah nilai ratarata yang dihasilkan dari semua responden satu jenis alat tangkap untuk satu kriteria. Skor yang diberikan berkisaran antara 1-3, semakin tinggi berbanding lurus dengan semakin tinggi pula keandalan dari aspek tersebut. Sebaliknya semakin rendah skor yang diberikan maka destruktif unit penangkapan ikan tinggi (Silaban et al. 2017).

Hasil observasi dan wawancara dari responden menghasilkan nilai skor untuk setiap kriteria-kriteria digunakan. Hasil tersebut dilakukan analisis untuk menentukan urutan prioritas alat tangkap unggulan. Hasil analisis data alat tangkap unggulan ikan pelagis tertangkap memiliki data akhir seperti Tabel 2.

Tabel 1. Aspek teknik, biologi, sosial, dan ekonomi yang digunakan dalam menentukan alat

\begin{tabular}{|c|c|c|c|}
\hline No & Aspek & Kriteria & Keterangan Skor \\
\hline \multirow[t]{14}{*}{1} & Teknis & a. Lama trip & Data riil \\
\hline & & b. Metode penangkapan & $1=$ sulit dalam pengoerasiannya \\
\hline & & & $2=$ agak sulit dalam pengoperasiannya \\
\hline & & & $3=$ mudah dalam pengoperasiannya \\
\hline & & c. Daya jangkau operasi & Data riil \\
\hline & & d. Selektifitas alat tangkap & $\begin{aligned} 1= & \text { tidak selektif }(\geq 3 \text { spesies dengan } \\
& \text { ukuran yang berbeda jauh) }\end{aligned}$ \\
\hline & & & $\begin{aligned} 2= & \text { cukup selektif ( } 3 \text { spesies dengan } \\
& \text { ukuran yang tidak berbeda jauh) }\end{aligned}$ \\
\hline & & & $\begin{aligned} 3= & \text { sangat selektif }(1 \text { spesies dengan } \\
& \text { ukuran yang sama) }\end{aligned}$ \\
\hline & & $\begin{array}{l}\text { e. Peguasaan dan penggunaan } \\
\text { teknologi dan alat bantu }\end{array}$ & $1=$ sulit dalam pengoerasiannya \\
\hline & & & $2=$ agak sulit dalam pengoperasiannya \\
\hline & & & $3=$ mudah dalam pengoperasiannya \\
\hline & & f. Penggunaan bahan bakar & $1=\geq 400$ liter \\
\hline & & & $2=\geq 200$ liter \\
\hline & & & $3=\leq 200$ liter \\
\hline 2 & Biologi & $\begin{array}{l}\text { a. Dampak terhadap habitat } \\
\text { dan biodiversity }\end{array}$ & $\begin{aligned} 1= & \text { sangat merusak (menyebabkan ke- } \\
& \text { matian beberapa spesies dan meru- } \\
& \text { sak habitat) }\end{aligned}$ \\
\hline
\end{tabular}
tangkap unggulan ikan pelagis 


\begin{tabular}{|c|c|c|c|}
\hline & & & $\begin{aligned} 2= & \text { cukup merusak (menyebabkan ke- } \\
& \text { matian beberapa spesies dan tidak } \\
& \text { merusak habitat) }\end{aligned}$ \\
\hline & & & $\begin{aligned} 3= & \text { tidak merusak (aman bagi spesies } \\
& \text { dan tidak merusak habitat) }\end{aligned}$ \\
\hline & & b. Komposisi hasil tangkapan & $1=\geq 5$ \\
\hline & & & $2=\geq 3$ \\
\hline & & & $3=\leq 3$ \\
\hline & & c. By-catch & $\begin{aligned} 1= & \text { tinggi }(\geq 3 \text { jenis ikan yang tidak } \\
& \text { laku dijual di pasar })\end{aligned}$ \\
\hline & & & $\begin{aligned} 2= & \text { sedang ( } 3 \text { jenis ikan dan ada yang } \\
& \text { laku dijual di pasar) }\end{aligned}$ \\
\hline & & & $\begin{aligned} 3= & \text { rendah }(\leq 3 \text { jenis ikan dan ada } \\
& \text { yang laku dijual pasar })\end{aligned}$ \\
\hline 3 & Sosial & $\begin{array}{l}\text { a. Dapat diterima secara } \\
\text { sosial }\end{array}$ & $\begin{aligned} 1= & \text { rendah (alat tangkap bertentangan } \\
& \text { dengan budaya yang ada dan } \\
& \text { bertentangan dengan peraturan } \\
& \text { yang ada) }\end{aligned}$ \\
\hline & & & $\begin{aligned} 2= & \text { sedang (alat tangkap bertentangan } \\
& \text { dengan peraturan yang ada) }\end{aligned}$ \\
\hline & & & $\begin{aligned} 3= & \text { tinggi (alat tangkap diterima baik } \\
& \text { oleh masyarakat) }\end{aligned}$ \\
\hline & & b. Jumlah ABK & Data riil \\
\hline & & c. Aspek hukum & 1 = ilegal \\
\hline & & & $2=$ modifikasi \\
\hline & & & $3=$ legal \\
\hline 4 & Ekonomi & a. Tingkat keuntungan & Data riil \\
\hline & & b. Biaya operasional per trip & $1=\geq 1.000 .000$ \\
\hline & & & $2=\geq 500.000$ \\
\hline & & & $3=\leq 500.000$ \\
\hline & & $\begin{array}{l}\text { c. Kontinuitas penerimaan } \\
\text { usaha }\end{array}$ & $\begin{array}{l}\text { Jumlah bulan alat tangkap bisa } \\
\text { dioperasikan untuk setiap tahun (data } \\
\text { riil) }\end{array}$ \\
\hline & & d. Pemasaran hasil tangkapan & $1=$ lokal (dalam kota) \\
\hline & & & $2=$ nasional (luar provinsi) \\
\hline & & & $3=$ ekspor (luar negeri) \\
\hline
\end{tabular}

Sumber: Modifikasi dari Astarini et al. 2011; Irnawati et al. 2011; Mustaruddin et al.2017; Wulandari et al. 2017.

Tabel 2. Hasil gabungan standarisasi alat tangkap berdasarkan aspek teknik, biologi, sosial dan ekonomi

\begin{tabular}{|c|c|c|c|c|c|}
\hline No & Alat Tangkap & V1 & $\mathbf{V n}$ & VAG & Urutan Prioritas \\
\hline 1 & & & & & 1 \\
\hline 2 & & & & & 2 \\
\hline dst & & & & & dst \\
\hline
\end{tabular}

Keterangan:

$\mathrm{V} \quad$ : Nilai standarisasi aspek

VAG : Jumlah nilai standarisasi aspek teknik, biologi, sosial dan ekonomi

UP : Urutan Prioritas 


\section{HASIL DAN PEMBAHASAN}

Produksi perikanan tangkap Kota Bengkulu apabila dibandingkan dengan potensi yang ada, pemanfaatannya belum berjalan optimal atau belum mencapai target yang diinginkan. Adapun data perkembangan produksi ikan pelagis pada tahun 2010-2017 di Kota Bengkulu disajikan pada Gambar 1. Perkembangan produksi ikan pelagis pada tahun 2010-2012 selalu mengalami penurunan. Produksi ikan pelagis pada tahun 2013-2015 mulai mengalami peningkatan yang signifikan. Peningkatan produksi ikan pelagis pada tahun 20152017 mengalami peningkatan yang stabil. Produksi ikan pelagis terendah terdapat pada tahun 2012, sedangkan produksi ikan pelagis tertinggi terdapat pada tahun 20152017.

Produksi ikan pelagis di Kota Bengkulu belum berjalan secara optimal. Pengoptimalan hasil produksi memerlukan informasi sebaran daerah penangkapan ikan yang menjadi daerah pengoperasian alat tangkap nelayan Kota Bengkulu. Sebaran daerah penangkapan ikan pelagis yang di tangkap oleh nelayan Kota Bengkulu dapat dilihat pada Gambar 2.

Daerah yang dimanfaatkan nelayan Kota Bengkulu untuk menangkap ikan pelagis berada di sekitar Pulau Tikus, Pulau Mega, dan Pulau Enggano (Gambar 2). Pemanfaatan daerah penangkapan di sekitar Pulau Tikus, mayoritas dimanfaatkan oleh nelayan yang memiliki alat tangkap dan kapal dengan ukuran kecil dan tidak dilengkapi oleh GPS. Alat tangkap yang dioperasikan di sekitar Pulau Tikus adalah pukat lore, pukat irik, rawai, pancing tonda, dan gillnet permukaan.

Adapun sebaran daerah penangkapan ikan di sekitar Pulau mega dan Pulau Enggano biasanya ditangkap oleh nelayan yang mengoperasikan alat tangkap dengan ukuran kapal yang cukup besar dan memanfaatkan alat bantu seperti rumpon yang terdapat di sekitar pulau. Adapun alat tangkap yang dioperasikan di sekitar Pulau Mega dan Pulau Enggano adalah pukat payang, pancing tonda, bagan perahu, gillnet dasar, dan purse seine. Disamping itu, nelayan yang menggunakan alat tangkap dengan ukuran kapal yang cukup besar juga sering menangkap ikan di sekitar Pulau Tikus.

Apabila penangkapan ikan dilakukan di daerahyang sama dengan waktu yanglama, maka akan mengakibatkan ekploitasi. Selain itu pemanfaatan daerah penangkapan ikan di lokasi yang sama akan mengakibatkan dampak sosial seperti terjadinya konflik antar nelayan. Simbolon (2011) menyatakan bahwa ikan pelagis merupakan kelompok ikan yang sebagian besar hidupnya berada pada lapisan permukaan perairan hingga kolom air, sehingga membuat sebaran daerah penangkapan ikan lebih luas. Oleh karena itu nelayan Kota Bengkulu bisa memanfaatkan daerah penangkapan ikan yang belum termanfaatkan. Sehingga akan menghindari terjadinya ekploitasi dan konflik antar nelayan. Penangkapan ikan yang dilakukan oleh nelayan dengan menggunakan beranekaragam alat tangkap.

Alat tangkap yang digunakan nelayan untuk menangkap ikan pelagis dilakukan penilaian aspek teknik didasarkan pada beberapa kriteria. Kriteria-kriteria tersebut yaitu lama trip, metode penangkapan, daya jangkau operasi, selektifitas alat tangkap, penguasaan dan penggunaan teknologi dan alat bantu, dan penggunaan bahan bakar. Hasil analisis penilaian aspek teknik disajikan pada Tabel 3.

Tabel 3 menunjukkan bahwa penilaian dan standarisasi aspek teknik menghasilkan alat tangkap yang memiliki urutan prioritas tertinggi adalah pancing tonda, pukat payang, dan bagan perahu. Keunggulan pancing tonda, pukat payang, dan bagan perahu dari aspek teknik yaitu metode pengoperasian tergolong mudah. Pancing tonda, pukat payang, dan purse seine memiliki daya jangkau pengoperasian yang jauh dengan menggunakan alat bantu rumpon. Ilham dan Tajuddin (2016) menyatakan bahwa semakin baik armada yang digunakan maka jangkauan operasi semakin jauh.

Penilaian aspek biologi dilihat dari beberapa kriteria yaitu dampak terhadap habitat dan biodiversity, komposisi hasil tangkapan, dan by-catch. Hasil analisis aspek biologi disajikan pada Tabel 4 .

Tabel 4 menunjukkan bahwa alat tangkap yang menjadi urutan prioritas tertinggi dari penilaian dan standarisasi aspek biologi adalah pukat payang, pancing tonda, dan bagan perahu. Keunggulan alat tangkap pukat payang, pancing tonda, dan bagan perahu dari aspek biologi yaitu pengoperasian alat tangkap tidak berdampak terhadap habitat dan biodiversity. Dimana alat tangkap unggulan merupakan alat tangkap yang memiliki kriteria ramah lingkungan dengan tidak menghasilkan dampak terhadap habitat (Dewanti et al. 
2018). Alat tangkap unggulan merupakan alat tangkap yang tidak menangkap ikanikan yang tidak menjadi target tangkapan (by-catch) (Lumaksono \& Hozairi 2017), dimana by-catch alat tangkap pukat payang, pancing tonda, dan bagan perahu masih tergolong rendah dan dikategorikan dapat dijual di pasar.
Penentuan alat tangkap unggulan ikan pelagis juga dilihat berdasarkan aspek sosial. Penilaian aspek sosial didasarkan pada beberapa kriteria yaitu dapat diterima secara sosial, jumlah ABK, dan aspek hukum. Hasil penilaian dan standarisasi dari aspek sosial disajikan pada Tabel 5 .

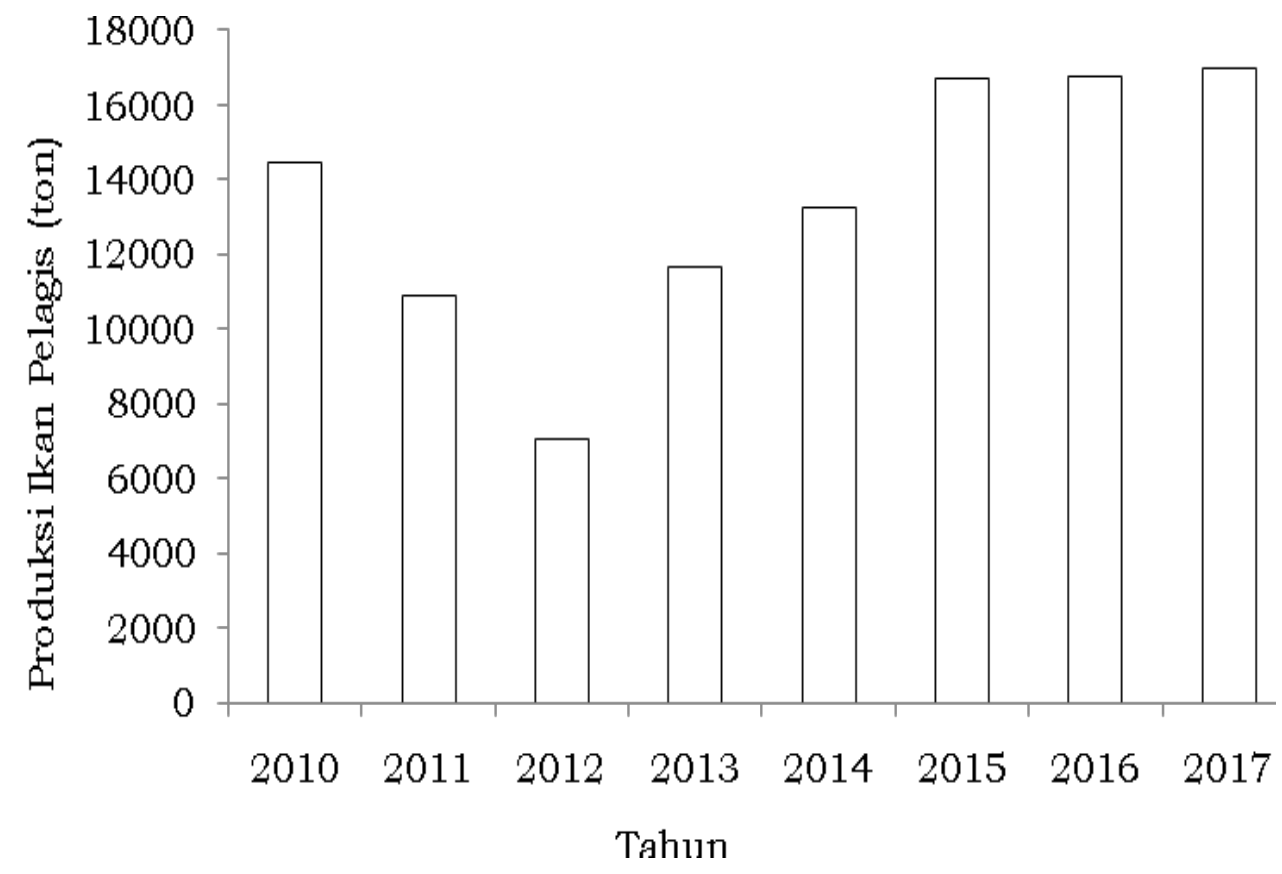

Gambar 1. Produksi ikan pelagis di Kota Bengkulu

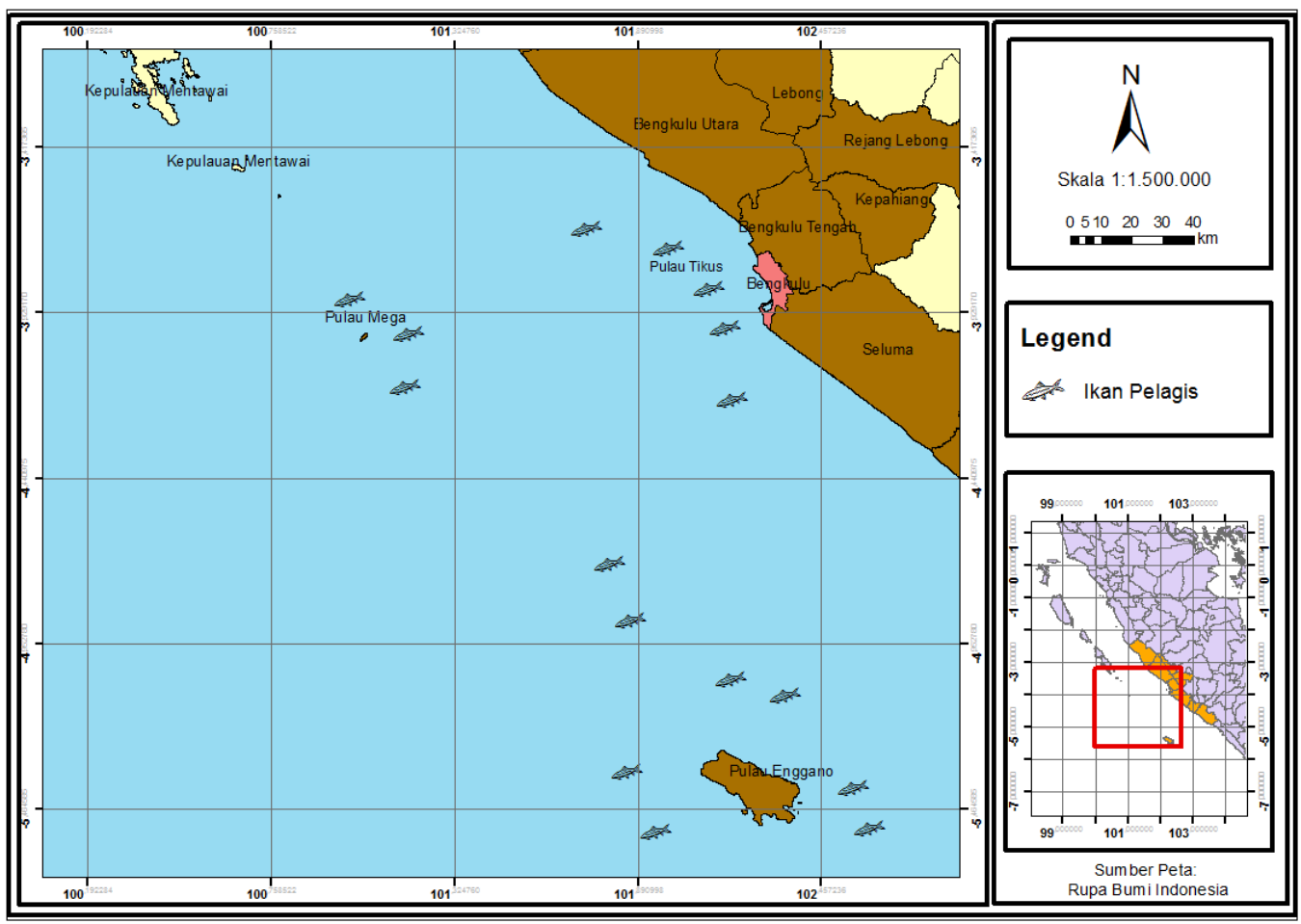

Gambar 2. Sebaran daerah penangkapan ikan pelagis di Kota Bengkulu 
Tabel 3. Penilaian dan standarisasi penilaian aspek teknik

\begin{tabular}{|c|c|c|c|c|c|c|c|c|c|c|c|c|c|c|c|}
\hline No & lat Tangkap & $\mathbf{x} 1$ & 1 & $\mathbf{x} 2$ & V2 & $\mathbf{x 3}$ & 13 & $\mathrm{x} 4$ & 74 & $\mathbf{x} 5$ & v5 & $\mathbf{x 6}$ & v6 & VA & UP \\
\hline 1 & nat & 11 & 0,00 & 3 & 1,00 & 53097 & 0,15 & 2 & 0,00 & 3 & 1,00 & 3 & 1,00 & 3,16 & 2 \\
\hline 2 & Pukat lore & 8 & 0,00 & 3 & 1,00 & 7241 & 0,02 & 2 & 0,00 & 2 & 0,00 & 3 & 1,00 & 2,02 & 8 \\
\hline 3 & Puka & 8 & 0,00 & 3 & 1,00 & 1556 & 0,00 & 2 & 0,00 & 2 & 0,00 & 3 & 1,00 & 2,00 & 9 \\
\hline 4 & Rawai & 121 & 0,16 & 3 & 1,00 & 273852 & 0,79 & 2 & 0,00 & 2 & 0,00 & 3 & 0,75 & 2,70 & 5 \\
\hline 5 & Pancing tonda & 266 & 0,36 & 3 & 1,00 & 289620 & 0,84 & 2 & 0,00 & 3 & 1,00 & 2 & 0,30 & 3,50 & 1 \\
\hline 6 & Bagan tancap & 12 & 0,01 & 3 & 1,00 & 17 & 0,00 & 2 & 0,00 & 3 & 1,00 & 3 & 1,00 & 3,01 & 4 \\
\hline 7 & Bagan perahu & 226 & 0,31 & 2 & 0,00 & 129525 & 0,38 & 2 & 0,00 & 3 & 1,00 & 1 & 0,00 & 1,68 & 10 \\
\hline 8 & Gillnet dasar & 720 & 1,00 & 3 & 1,00 & 53633 & 0,16 & 2 & 0,00 & 3 & 1,00 & 1 & 0,00 & 3,16 & 3 \\
\hline 9 & $\begin{array}{l}\text { Gillnet } \\
\text { permukaan }\end{array}$ & 9 & 0,00 & 3 & 1,00 & 14159 & 0,04 & 2 & 0,00 & 2 & 0,00 & 3 & 1,00 & 2,04 & 7 \\
\hline 10 & Purse seine & 432 & 0,60 & 2 & 0,00 & 344786 & 1,00 & 2 & 0,00 & 3 & 1,00 & 1 & 0,00 & 2,60 & 6 \\
\hline
\end{tabular}

Keterangan:

$\mathrm{X} 1$ : Lama trip

X2 : Metode penangkapan

X3 : Daya jangkau operasi

X4 : Selektifitas alat tangkap

X5 : Penguasaan dan penggunaan teknologi dan alat bantu

X6 : Penggunaan bahan bakar

$\mathrm{V} \quad$ : Fungsi nilai dari kriteria

VA : Fungsi nilai dari aspek teknik

UP : Urutan prioritas

Tabel 4. Penilaian dan standarisasi aspek biologi

\begin{tabular}{clcccccccc}
\hline No & Alat Tangkap & $\mathbf{X 1}$ & $\mathbf{V 1}$ & $\mathbf{X 2}$ & $\mathbf{V 2}$ & $\mathbf{X 3}$ & V3 & VA & UP \\
\hline 1 & Pukat payang & 3,00 & 1,00 & 1,40 & 0,93 & 3,00 & 1,00 & 2,93 & 1 \\
2 & Pukat lore & 2,00 & 0,00 & 1,30 & 0,70 & 3,00 & 1,00 & 1,70 & 8 \\
3 & Pukat irik & 2,00 & 0,00 & 1,20 & 0,47 & 3,00 & 1,00 & 1,47 & 9 \\
4 & Rawai & 3,00 & 1,00 & 1,30 & 0,70 & 3,00 & 1,00 & 2,70 & 4 \\
5 & Pancing tonda & 3,00 & 1,00 & 1,40 & 0,93 & 3,00 & 1,00 & 2,93 & 2 \\
6 & Bagan tancap & 3,00 & 1,00 & 1,43 & 1,00 & 2,00 & 0,00 & 2,00 & 6 \\
7 & Bagan perahu & 3,00 & 1,00 & 1,40 & 0,93 & 3,00 & 1,00 & 2,93 & 3 \\
8 & Gillnet dasar & 2,00 & 0,00 & 1,00 & 0,00 & 3,00 & 1,00 & 1,00 & 10 \\
9 & Gillnet permukaan & 3,00 & 1,00 & 1,40 & 0,93 & 2,00 & 0,00 & 1,93 & 7 \\
10 & Purse seine & 3,00 & 1,00 & 1,29 & 0,67 & 3,00 & 1,00 & 2,67 & 5 \\
\hline
\end{tabular}

Keterangan:

X1 : Dampak terhadap habitat dan biodiversity

X2 : Komposisi hasil tangkapan

X3 : By-catch

$\mathrm{V} \quad$ : Fungsi nilai dari kriteria

VA : Fungsi nilai dari aspek biologi

UP : Urutan prioritas

Berdasarkan penilaian dan standarisasi dari aspek sosial terpilih alat tangkap unggulan untuk ikan pelagis yaitu purse seine, bagan perahu, dan pancing tonda (Tabel 5). Nilai VA dari purse seine adalah 2,00, bagan perahu 1,45, dan pancing tonda 1,06. Alat tangkap purse seine, bagan perahu, dan pancing tonda memiliki keuntungan dari aspek sosial yaitu dapat diterima secara sosial. Lumaksono dan Hozairi (2017) menyatakan bahwa alat tangkap yang menjadi alat tangkap unggulan 
dilihat dari aspek sosial dapat diterima baik oleh masyarakat nelayan. Purse seine dan bagan perahu dapat menyerap tenaga kerja, karena membutuhkan ABK yang banyak berkisar antara 24-50 orang (purse seine) dan 15-20 orang (bagan perahu). Semakin tinggi unit penangkapan yang digunakan maka akan membutuhkan tenaga kerja (ABK) dalam jumlah cukup banyak (Setyaningrum 2013). Selain itu berdasarkan dari aspek hukum alat tangkap purse seine, bagan perahu, dan pancing tonda sudah legal yaitu dilengkapi dengan surat izin pengoperasian dan lain-lain.

Penilaian aspek ekonomi didasarkan pada beberapa kriteria. Kriteria penilaian aspek ekonomi yaitu tingkat keuntungan, biaya operasi per trip, kontinuitas penerimaan usaha, dan pemasaran hasil tangkapan. Penilaian aspek ekonomi dalam penentuan alat tangkap unggulan untuk ikan pelagis dapat dilihat pada Tabel 6 .

Tabel 6 menunjukkan bahwa hasil penilaian dan standarisasi aspek ekonomi menghasilkan alat tangkap yang memiliki urutan prioritas tertinggi yaitu bagan perahu, purse seine, dan pukat payang. Keunggulan alat tangkap bagan perahu, purse seine, dan pukat payang dari aspek ekonomi yaitu memiliki tingkat keuntungan yang cukup tinggi untuk setiap trip penangkapan. Berkembangnya alat tangkap di suatu daerah dapat dilihat dari kondisi ekonomi yaitu tingkat keuntungan apakah alat tangkap tersebut memiliki tingkat keuntungan yang tinggi sehingga dapat dikatakan alat tangkap unggulan (Lumaksono dan Hozairi 2017). Selain itu, hasil tangkapan alat tangkap bagan perahu, purse seine, dan pukat payang kebanyakan pemasarannya sudah mencapai luar provinsi.

Penentuan alat tangkap unggulan untuk ikan pelagis tidak hanya dilihat dari satu aspek tetapi secara simultan dari keempat aspek. Alat tangkap terpilih menjadi alat tangkap unggulan merupakan alat tangkap yang memiliki kemampuan terbaik, ramah lingkungan, dapat diterima oleh masyarakat/tidak menimbulkan konflik, dan memberikan keuntungan bagi nelayan secara finansial (Wiyono 2011). Hasil gabungan standarisasi aspek teknik, biologi, sosial, dan ekonomi disajikan pada Tabel 7.

Tabel 7 menunjukkan hasil gabungan standarisasi alat tangkap ikan pelagis diperoleh bahwa alat tangkap yang memiliki prioritas menjadi alat tangkap unggulan adalah purse seine, bagan perahu, dan pancing tonda. Alat tangkap purse seine menempati urutan prioritas tertinggi, urutan kedua bagan perahu, dan urutan ketiga pancing tonda. Nilai fungsi akhir pengambilan keputusan (VAG) purse seine sebesar 9,66 diikuti oleh bagan perahu 9,06, dan pancing tonda 9,05.

Tabel 5. Penilaian dan standarisai aspek sosial

\begin{tabular}{clcccccccc}
\hline No & Alat Tangkap & $\mathbf{X 1}$ & $\mathbf{V 1}$ & $\mathbf{X 2}$ & $\mathbf{V 2}$ & $\mathbf{X 3}$ & V3 & VA & UP \\
\hline 1 & Pukat payang & 3,00 & 0,00 & 9 & 0,21 & 1,00 & 0,00 & 0,21 & 4 \\
2 & Pukat lore & 3,00 & 0,00 & 4 & 0,09 & 1,00 & 0,00 & 0,09 & 6 \\
3 & Pukat irik & 3,00 & 0,00 & 2 & 0,02 & 1,00 & 0,00 & 0,02 & 9 \\
4 & Rawai & 3,00 & 0,00 & 3 & 0,04 & 1,00 & 0,00 & 0,04 & 8 \\
5 & Pancing tonda & 3,00 & 0,00 & 4 & 0,06 & 2,00 & 1,00 & 1,06 & 3 \\
6 & Bagan tancap & 3,00 & 0,00 & 1 & 0,00 & 1,00 & 0,00 & 0,00 & 10 \\
7 & Bagan perahu & 3,00 & 0,00 & 18 & 0,45 & 2,00 & 1,00 & 1,45 & 2 \\
8 & Gillnet dasar & 3,00 & 0,00 & 5 & 0,10 & 1,00 & 0,00 & 0,10 & 5 \\
9 & Gillnet permukaan & 3,00 & 0,00 & 3 & 0,04 & 1,00 & 0,00 & 0,04 & 7 \\
10 & Purse seine & 3,00 & 0,00 & 39 & 1,00 & 2,00 & 1,00 & 2,00 & 1 \\
\hline
\end{tabular}

Keterangan:

X1 : Dapat diterima secara sosial

$\mathrm{X} 2$ : Jumlah ABK

X3 : Aspek hukum

$\mathrm{V} \quad$ : Fungsi nilai dari kriteria

VA : Fungsi nilai dari aspek sosial

UP : Urutan prioritas 
Tabel 6. Penilaian dan standarisasi aspek ekonomi

\begin{tabular}{clcccccccccc}
\hline No & Alat Tangkap & $\mathbf{X 1}$ & V1 & $\mathbf{X 2}$ & V2 & $\mathbf{X 3}$ & V3 & $\mathbf{X 4}$ & V4 & VA & UP \\
\hline 1 & Pukat payang & 31700000 & 0,11 & 3,00 & 1,00 & 12,00 & 1,00 & 1,00 & 0,00 & 2,11 & 3 \\
2 & Pukat lore & 6000000 & 0,02 & 3,00 & 1,00 & 4,80 & 0,08 & 1,00 & 0,00 & 1,09 & 9 \\
3 & Pukat irik & 2830000 & 0,01 & 3,00 & 1,00 & 12,00 & 1,00 & 1,00 & 0,00 & 2,01 & 4 \\
4 & Rawai & 14100000 & 0,05 & 1,80 & 0,40 & 4,20 & 0,00 & 1,10 & 0,10 & 0,55 & 10 \\
5 & Pancing tonda & 16100000 & 0,05 & 1,00 & 0,00 & 12,00 & 1,00 & 1,50 & 0,50 & 1,55 & 7 \\
6 & Bagan tancap & 1428571 & 0,00 & 3,00 & 1,00 & 12,00 & 1,00 & 1,00 & 0,00 & 2,00 & 5 \\
7 & Bagan perahu & 280000000 & 1,00 & 1,00 & 0,00 & 12,00 & 1,00 & 2,00 & 1,00 & 3,00 & 1 \\
8 & Gillnet dasar & 73333333 & 0,26 & 1,00 & 0,00 & 12,00 & 1,00 & 1,00 & 0,00 & 1,26 & 8 \\
9 & Gillnet & \multirow{2}{*}{5130000} & 0,01 & 3,00 & 1,00 & 8,60 & 0,56 & 1,00 & 0,00 & 1,58 & 6 \\
10 & permukaan & & & & & & & & & \\
10
\end{tabular}

Keterangan:

$\mathrm{X} 1$ : Tingkat keuntungan

X2 : Biaya operasional per trip

X3 : Kontinuitas penerimaan usaha

$\mathrm{X} 4$ : Pemasaran hasil tangkapan

$\mathrm{V} \quad$ : Fungsi nilai dari kriteria

VA : Fungsi nilai dari aspek ekonomi

UP : Urutan prioritas

Tabel 7. Hasil standarisasi gabungan alat tangkap ikan pelagis berdasarkan aspek teknik, aspek biologi, aspek sosial, dan aspek ekonomi

\begin{tabular}{clcccccc}
\hline No & Alat Tangkap & V1 & V2 & V3 & V4 & VAG & UP \\
\hline 1 & Pukat payang & 3,16 & 2,93 & 0,21 & 2,11 & 8,41 & 4 \\
2 & Pukat lore & 2,02 & 1,70 & 0,09 & 1,09 & 4,90 & 10 \\
3 & Pukat irik & 2,00 & 1,47 & 0,02 & 2,01 & 5,50 & 9 \\
4 & Rawai & 2,70 & 2,70 & 0,04 & 0,55 & 5,98 & 6 \\
5 & Pancing tonda & 3,50 & 2,93 & 1,06 & 1,55 & 9,05 & 3 \\
6 & Bagan tancap & 3,01 & 2,00 & 0,00 & 2,00 & 7,01 & 5 \\
7 & Bagan perahu & 1,68 & 2,93 & 1,45 & 3,00 & 9,06 & 2 \\
8 & Gillnet dasar & 3,16 & 1,00 & 0,10 & 1,26 & 5,52 & 8 \\
9 & Gillnet permukaan & 2,04 & 1,93 & 0,04 & 1,58 & 5,59 & 7 \\
10 & Purse seine & 2,60 & 2,67 & 2,00 & 2,40 & 9,66 & 1 \\
\hline
\end{tabular}

Keterangan:

V1 : Nilai standarisasi aspek teknik

V2 : Nilai standarisasi aspek biologi

V3 : Nilai standarisasi aspek sosial

V4 : Nilai standarisasi aspek ekonomi

VAG : Jumlah nilai standarisasi aspek teknik, biologi, sosial dan ekonomi

UP : Urutan prioritas alat tangkap unggulan

Alat tangkap yang menempati prioritas tertinggi atau terpilih menjadi alat tangkap unggulan merupakan alat tangkap yang unggulan dari segi aspek teknik, biologi, sosial, dan ekonomi. Alat tangkap tersebut efektif digunakan (aspek teknik), tidak merusak atau mengganggu kelestarian sumber daya ikan (aspek biologi), dapat diterima oleh masyarakat nelayan (aspek sosial), dan memiliki tingkat keuntungan yang tinggi (aspek ekonomi) (Haluan dan Nurani 1988 dalam Tahapary et al. 2010; 
Simbolon et al. 2011). Alat tangkap yang tidak terpilih menjadi alat tangkap unggulan tidak perlu dihapuskan, tetapi dapat dijadikan sebagai alat tangkap alternatif yang disesuaikan dengan daya dukung lingkungan dan tujuan pengembangan perikanan (pantai, lepas pantai, laut dalam, dan lain-lain) (Wiyono 2011).

\section{KESIMPULAN DAN SARAN}

\section{Kesimpulan}

Daerah penangkapan ikan pelagis tersebar di sekitar Pulau Tikus, Pulau Mega, dan Pulau Enggano. Berdasarkan hasil standarisasi gabungan aspek teknik, biologi, sosial, dan ekonomi terpilih alat tangkap unggulan untuk ikan pelagis yaitu purse seine, bagan perahu, dan pancing tonda.

\section{Saran}

Dibutuhkan penelitian lanjutan dalam penentuan daerah penangkapan satu spesies ikan pelagis dan mengetahui secara lebih rinci alat tangkap unggulan satu spesies ikan pelagis tersebut. Sehingga dapat diketahui satu spesies tersebut termasuk ekonomis penting dan komoditas unggulan atau tidak.

\section{DAFTAR PUSTAKA}

Astarini JE, Haluan J, Wisudo SH, Monintja D, Simbolon D. 2011. Pengembangan Perikanan Tangkap Berbasis Code of Conduct for Responsible Fisheries (CCRF) di Ternate, Provinsi Maluku Utara. Buletin PSP. 19(1) : 127-137.

Dewanti LP, Mahdiana I, Zidni I, Herawati H. 2018. Evaluasi Selektivitas dan Keramahan Lingkungan Alat Tangkap di Kabupaten Pangandaran Provinsi Jawa Barat. Jurnal Airaha. 7(1) : 030037.

[DKP] Dinas Perikanan dan Kelautan Kota Bengkulu. 2017. Laporan Tahunan Produksi Perikanan Tangkap dan Alat Tangkap Kota Bengkulu.

Himelda, Wiyono ES, Mustaruddin. 2012. Seleksi Jenis Alat Tangkap dan Teknologi yang Tepat dalam Pemanfaatan Sumberdaya Lemuru di Selat Bali. Jurnal Buletin PSP. 20(1) : 89-102.
Ilham, Tajuddin M. 2016. Pemetaan Daerah Penangkapan Ikan Dengan Pendekatan Ruang di Perairan Kabupaten Sumba Timur. Jurnal Biologi Tropik. 16(2) : 56-63.

Irnawati R, Simbolon D, Wiryawan B, Murdiyanto B, Nurani TW. 2011. Analisis Komoditas Unggulan Perikanan Tangkap di Taman Nasional Karimunjawa. Jurnal Saintek Perikanan. 7(1) : 1-9.

Ispahdianto D, Fitri ADP, Asriyanto. 2016. Analisis Hasil Tangkapan Ikan Kembung (Rastrelliger sp.) dan Cumi-Cumi (Lolligo sp.) pada Alat Tangkap Mini Purse Seine di Perairan Morodemak, Kabupaten Demak Jawa Tengah. Journal of Fisheries Resources Utilization Management and Technology. 5(1) : 153-161.

Lumaksono H, Hozairi. 2017. Sistem Pendukung Keputusan untuk Menentukan Alat Tangkap yang Sesuai bagi Nelayan di Madura Menggunakan Metode AHP-TOPSIS. JUrnal Seminar MASTER. 2548-6527.

Mustaruddin, Baskoro MS, Kandi O, Nasruddin. 2017. Environmental and Technical Aproach in The Selection of Fishing Gear Featured in WPP 571 Aceh. IJSBAR. 31(3) : 44-53.

Pregiwati LA, Wiryawan B, Wisudo SH, Satria A. 2017. Seleksi Komoditas dan Teknologi Penangkapan Ikan Unggulan di Kabupaten Kepulauan Anambas. Jurnal Marine Fisheries. 8(1) : 113-122.

Setyaningrum EW. 2013. Penentuan Jenis Alat Tangkap Ikan Pelagis yang Tepat dan Berkelanjutan dalam Mendukung Peningkatan Perikanan Tangkap di Muncar Kabupaten Banyuwangi Indonesia. J-PAL. 4(2) : 45-50.

Shabrina NN, Sunarto, Hamdani H. 2017. Penentuan Daerah Penangkapan Ikan Tongkol Berdasarkan Pendekatan Distribusi Suhu Permukaan Laut dan Hasil Tangkapan Ikan di Perairan Utara Indramayu Jawa Barat. Jurnal Perikanan dan Kelautan. 8(1) : 139145.

Silaban J, Mustaruddin, Soeboer DA. 2017. Penentuan Alat Tangkap Unggulan untuk Ikan Pelagis Kecil di Pelabuhanratu Sukabumi. Jurnal Albacore. 1(2) : 225-234.

Simbolon D, Purbayanto A, Astarini, Simanungkalit W. 2011. Eksplorasi Teknologi Tepat Guna dalam 
Penangkapan Kakap Putih (Lates calcarifer) di Kabupaten Mimika. Jurnal Teknologi Perikanan dan Kelautan. 1(2) : 11-23.

Simbolon D. 2011. Bioekologi dan Dinamika Daerah Penangkapan Ikan. Bogor. Departemen Pemanfaatan Sumberdaya Perikanan Fakultas Perikanan dan ilmu Kelautan, IPB.

Tahapary J, Simbolon D, Nurani TW. 2010. Strategi Pengembangan Perikanan Pelagis Kecil di Perairan Kabupaten Maluku Tenggara. Jurnal Forum Pascasarjana. 33(4) : 285-297.

Wiyono ES. 2011. Alat Tangkap Unggulan di Kabupaten Bangka Selatan, Provinsi Bangka Belitung. Jurnal Buletin PSP. 19 (3) : 229-238.

Wulandari U, Simbolon D, Wahju, RI. 2017. Seleksi Unit Penangkapan Ikan Tepat Guna di Pulau Enggano, Provinsi Bengkulu. Jurnal Albacore. 1(1) : 021-036. 